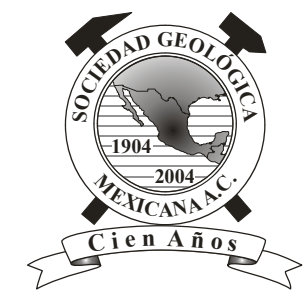

\title{
Fenómenos diagenéticos en calizas del Jurásico-Cretácico de un sector de las cuencas de Huimanguillo-Comalcalco-Alto de Jalpan y primeras observaciones mediante microscopio electrónico de barrido y microtomografía 3D
}

\author{
Luis E. González-Ruiz ${ }^{1,2, *}$, Eduardo González-Partida ${ }^{3}$, Luis Martínez ${ }^{4}$, Jacques Pironon ${ }^{1}$, \\ Antoni Camprubí ${ }^{5}$, Marina Vega-González ${ }^{3}$ \\ ${ }^{1}$ Université de Lorraine, CNRS, CREGU, GeoRessources lab, F-54506, Vandoeuvre-lès-Nancy, Francia. \\ ${ }^{2}$ Centro Nacional de Investigación Avanzada en Petrofísica y GEOMINCO S.A. de C.V., 076100, Santiago de Querétaro, Qro., \\ México. \\ ${ }^{3}$ Centro de Geociencias, Universidad Nacional Autónoma de México, Campus Juriquilla, 07600, Santiago de Querétaro, Qro., \\ México. \\ ${ }^{4}$ École et Observatoire des Sciences de la Terre, UMR CNRS/UdS 7516, Université de Strasbourg. 1 rue Blessig, 67084 Strasbourg \\ Cedex, Francia. \\ ${ }^{5}$ Instituto de Geología, Universidad Nacional Autónoma de México, Ciudad Universitaria, Coyoacán, D.F., 04510, México.
}

*1_e_g_r@hotmail.com

\begin{abstract}
Resumen
Los sistemas petroleros de la cuenca del Sureste (Tabasco, México) se caracterizan por presentar rocas generadoras principalmente del Jurásico Superior, rocas almacén del Cretácico y rocas sello del Cretácico Superior-Cenozoico. Generalmente, la mayoría de estos reservorios refleja una compleja historia diagenética que depende de la porosidad y permeabilidad imperantes. El propósito de este trabajo es ilustrar de qué manera herramientas analíticas como el microscopio electrónico de barrido (MEB) y la microtomografía 3D de rayos-X permiten entender por qué aún a bajas permeabilidades los hidrocarburos se acumulan y fluyen.

Las muestras de roca observadas al MEB se encuentran fuertemente alteradas por procesos diagenéticos de corrosión-disoluciónprecipitación, con desarrollo de fracturas, disolución, estilolitas, cierre de microporosidad (vugs), decarbonatación, y dedolomitización. La sucesión paragenética de dichos procesos diagenéticos puede esquematizarse de la siguiente forma: dolomita $\rightarrow$ calcita $_{1} \rightarrow$

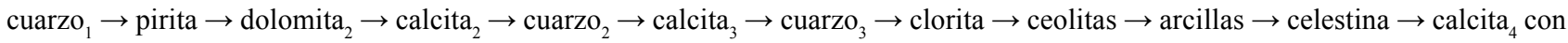
hidrocarburos. Destaca la presencia generalizada de cuarzo y el reemplazamiento parcial de algunos fósiles por pirita framboidal. Esta última, las arcillas y las zeolitas generalmente ocupan espacios dejados por los cristales de dolomita corroída, e igualmente se encuentran dentro de la porosidad (vugs) y en fracturas, como una etapa intermedia a tardía en la secuencia paragenética y esta caracterizada por las siguientes etapas:

(1) cementación de los carbonatos,

(2) alteraciones termobáricas, asociadas con la introducción de fluidos caracterizados mediante microtermometría de inclusiones fluidas: a. en dolomita, con salinidades entre $12 \%$ a $19 \%$ en peso equivalente $\mathrm{NaCl}$ y temperaturas de homogeneización (Th) entre 99 y $141^{\circ} \mathrm{C}$,

b. en cuarzo diagenético como relleno de porosidad y fracturas se obtuvieron salinidades entre $12 \%$ a $15 \%$ en peso equivalente $\mathrm{NaCl}$ y $\mathrm{Th}$ entre 112 y $131^{\circ} \mathrm{C}$,

c. en calcita de la primera generación se obtuvieron salinidades entre $12 \%$ a $14 \%$ en peso equivalente $\mathrm{NaCl}$ y $\mathrm{Th}$ entre 110 y $149^{\circ} \mathrm{C}$,

(3) una etapa ulterior de corrosión.
\end{abstract}


Información novedosa obtenida por microtomografía de rayos-X revela que la mayoría de vugs no está interconectada, y que las muestras presentan abundantes fósiles distribuidos al azar en la matriz micrítica y orientados de acuerdo a la estratificación. Microfracturas y nano-poros de la matriz son en parte los responsables del desarrollo de vugs donde las cavidades se forman a partir de soluciones corrosivas que inicialmente generaron micro-brechas seguidas de un relleno parcial por cuarzo y calcita.

Palabras clave: Diagénesis, dolomitización, corrosión, disolución, precipitación, microtomografía.

\begin{abstract}
The petroleum systems of the Southeast basin (Tabasco, Mexico) are characterized by having source rocks mainly from the Upper Jurassic, Cretaceous storage rocks, and Upper Cretaceous to Cenozoic seal rocks. In general, most of these reservoirs reflect a complex diagenetic history that depends on the prevailing porosity and permeability. A new approach using tools such as scanning electron microscopy (SEM) and X-ray 3D microtomography contribute to the understanding of how hydrocarbons accumulate and flow even at low permeabilities.

The rock specimens observed by means of SEM are strongly altered by diagenetic processes of corrosion-dissolution-precipitation, which generated fractures, dissolution, stylolites, vug lining, decarbonatization, and dedolomitization. The paragenetic succession of such diagenetic processes can be schematized thus: dolomite ${ }_{1} \rightarrow$ calcite $_{1} \rightarrow$ quartz $_{1} \rightarrow$ pyrite $\rightarrow$ dolomite $_{2} \rightarrow$ calcite $_{2} \rightarrow$ quartz $_{2} \rightarrow$ calcite $_{3} \rightarrow$ quartz $_{3} \rightarrow$ chlorite $\rightarrow$ zeolites $\rightarrow$ clay minerals $\rightarrow$ celestine $\rightarrow$ calcite $_{4}$ with hydrocarbons. It is worth noting the widespread presence of quartz and the partial replacement of some fossils by framboidal pyrite. The latter, along with clays and zeolites usually occupy spaces left after the corrosion of dolomite crystals, and also occur within vugs and fractures, as an intermediate to late stage in the paragenetic sequence. The latter is characterized by the following stages:

(1) cementation of carbonates,

(2) thermobaric alteration, associated with the incursion of fluids that were characterized by means of microthermometry of fluid inclusions:

a. in dolomite, with salinities that range between 12 and $19 \mathrm{wt} \% \mathrm{NaCl}$ equiv., and temperatures of homogenization (Th) between 99 and $141^{\circ} \mathrm{C}$,

b. in diagenetic quartz in vugs and fractures, with salinities that range between 12 and $15 \mathrm{wt} \% \mathrm{NaCl}$ equiv., and Th between 112 and $131^{\circ} \mathrm{C}$,

c. in the earliest calcite, with salinities that range between 12 and $14 \mathrm{wt} . \% \mathrm{NaCl}$ equiv., and Th between 110 and $149{ }^{\circ} \mathrm{C}$,

(3) a late stage of corrosion.

New information obtained by means of X-ray microtomography reveals that most of the vugs are not interconnected, and that the samples have abundant fossils randomly distributed in the micritic matrix and oriented according to the stratification. Microfractures and nano-pores in the matrix are partially responsible for the development of the vugs where cavities are formed after corrosive solutions that initially generated micro-breccias, followed by a partial lining by quartz and calcite.
\end{abstract}

Keywords: diagenesis, dolomitization, corrosion, dissolution, precipitation, microtomography.

\section{Introducción}

En la Región Sur de México existen 120 campos petroleros (Petróleos Mexicanos, 2011). En los últimos años, esta zona ha producido aproximadamente el $35 \%$ del total de hidrocarburos del país, y cada año se incrementan sus reservas (Petróleos Mexicanos, 2012). De acuerdo con los trabajos de Medrano-Morales y Romero (1993), GuzmánVega y Mello (1999), Santamaría (2000), Santamaría y Horsfield (2000), Guzmán-Vega et al. (2001a, b), ÁngelesAquino y Cantú-Chapa (2001), Rosenfeld (2002), CantúChapa y Ortuño-Maldonado (2003), Holguín et al. (2005) y Magoon et al. (2009), en el área de estudio:

(1) la principal roca generadora es del Jurásico Superior;

(2) la roca almacén va desde niveles del Jurásico Superior
(Kimmeridgiano), donde predomina la presencia de intervalos de packstone de bioclastos recristalizados con microfracturas, se tiene alternancia con algunos intervalos de mudstone-wackestone $\mathrm{y}$, en menor cantidad, de intervalos de grainstone de oolitas correspondientes con un ambiente de depósito de plataforma, aunque en zonas profundas predomina la dolomitización;

(3) la roca almacén del Cretácico "medio" consiste en mudstone-wackestone recristalizadas, fracturadas y micro-fracturadas, formadas en un ambiente de cuenca;

(4) la roca almacén del Cretácico Superior consiste en mudstone-wackestone recristalizadas, fracturadas y micro-fracturadas con porosidad secundaria 
intercristalina y en microfracturas; $y$

(5) el sello del sistema está representado por espesores considerables de rocas arcillosas del Paleógeno y margas del Cretácico Superior.

Un sistema petrolero, es decir, la roca generadora, la roca almacén y la roca sello, es producto de la procedencia de los sedimentos, del ambiente de depósito y de la evolución de los paleofluidos (Bathurst, 1975; Budd et al., 1995; Flügel, 2004; González-Partida et al., 2008). Tales procesos determinan la intensidad de los fenómenos diagenéticos (Bathurst, 1975; Chillingarian et al., 1992; Horsfield y Rullkötter, 1994; Budd et al., 1995; Flügel, 2004). Así, el estudio en detalle de la sucesión de eventos diagenéticos de secuencias carbonatadas ha permitido determinar un conjunto de etapas de evolución que pueden llevar o no a la generación de un reservorio de hidrocarburos en rocas carbonatadas (Figura 1). Reeckmann y Friedman (1982), Esteban (2005), Esteban y Taberner (2005) y Salas et al., (2007), entre otros autores, propusieron que el enterramiento y diagénesis de los reservorios carbonatados a nivel mundial muestran un comportamiento común, las etapas se describen a continuación:

(I) La cementación de los carbonatos tiene una secuencia sistemática, incluyendo:

a. compactación y presión-disolución,

b. algunas discontinuidades menores en las distintas etapas de cementación, y

c. incremento de la temperatura, tal y como se observa en los estudios de inclusiones fluidas (González-Partida et al., 2008), lo cual implica la obliteración general de la porosidad y fracturas tempranas, aunque es posible que alguna de éstas se conserven hasta condiciones de diagénesis profunda.

(II) Alteraciones hidrotermales termobáricas (McCulloch y Naeser, 1989) locales, con la introducción de fluidos de relativamente alta temperatura (entre $\sim 150$ a 200 ${ }^{\circ} \mathrm{C}$ ) a favor de fracturas que actúan como canales de flujo, asociadas a brechas debidas a fracturación hidráulica (generalmente metanogénicas); En este estadio de evolución cesan los mecanismos de presióndisolución y apertura de las estilolitas formadas en etapas previas. Ocasionalmente, es posible encontrar trazas de las primeras etapas de migración de hidrocarburos. Esta etapa está ligada a dos posibles fenómenos diagenéticos principales:

a. reemplazamiento de la roca por dolomita de grano grueso, y

b. cementación masiva de calcita.

(III) Etapa tardía de corrosión generalizada de las fábricas anteriores, que se puede interpretar como el resultado de una mezcla y/o enfriamiento de las salmueras de cuenca (aguas de formación) junto con la invasión local de $\mathrm{CO}_{2}$ de origen orgánico, en asociación con una nueva etapa de fracturación hidráulica.

El resultado de los procesos diagenéticos señalados es variado y dependiente del lugar en donde se desarrolle la diagénesis, esto es, depende de la zona diagenética (Longman, 1980; Chillingarian et al., 1992; Purser et al., 1994; Lucia, 1995). El conocimiento de la composición química del agua de poro (intersticial) de los sedimentos es importante debido a que proporciona información relacionada a las reacciones químicas que se desarrollan en los sedimentos (Kharaka et al., 1985, 2004; Hanor, 1987; Hanor et al., 1988; Hanor, 1994). Si consideramos que la relación sólido-a-solución es bastante grande, es fácil imaginar que pequeños cambios en los sólidos durante la diagénesis influyen enormemente en la composición de la solución (Bickle et al., 1987; Bazin et al., 1997a, b). Partiendo de lo anterior, en ambientes carbonatados, durante el desplazamiento de los fluidos entre la roca, el comportamiento de éstos estará regido por las condiciones físico-químicas del medio circundante, de tal forma que el medio experimentará cambios constantes en su estado de equilibrio y en su estado de saturación. Ello se manifiesta como procesos repetitivos de disolución-precipitación, sinónimos también de generación o destrucción de porosidades y permeabilidades (Choquette y Pray, 1970; Moore, 1979; Longman, 1980).

En el ambiente diagenético de soterramiento profundo se forman vetillas de disolución y estilolitas, fisuras y microcavidades de tipo vugs (Figura 1). Las estilolitas y fracturas pueden ser corroídas y agrandadas debido a que los eventos corrosivos afectan a los cementos tardíos. Las etapas de maduración, expulsión y migración de los hidrocarburos hasta la carga del reservorio son parte de los procesos diagenéticos de soterramiento en los que las interacciones fluido-roca son de extrema importancia. Para el caso de las rocas carbonatadas, la porosidad y permeabilidad dependen en gran medida de los procesos de diagénesis profunda a la cual fueron sometidas las rocas, y en donde se producen fenómenos de construcción/destrucción de la porosidad y la permeabilidad. El sistema poroso así formado constituye una excelente red de canales (matriz-fractura-vugs, etc.) por los cuales pasan o se almacenan salmuera e hidrocarburos en las rocas. Sin embargo, esta forma de acumulación también es causa y condición para que se efectúen reorganizaciones diagenéticos, es decir, para que sucedan cambios físicos y químicos en los sedimentos que pueden obstruir o incrementar la porosidad originalmente adquirida.

En este trabajo se presenta una descripción de la sucesión de eventos diagenéticos de secuencias carbonatadas a profundidades de 2900 a $7000 \mathrm{~m}$ para un sector de la zona de Huimanguillo-Comalcalco-Alto de Jalpan de la cuenca del Sureste de México mediante técnicas petrográficas convencionales y microtomografía de rayos- $\mathrm{X}$ en $3 \mathrm{D}$, misma que se emplea por primera vez en México.

\section{Ambiente geológico de la cuenca}

La cuenca del Sureste de México (Figura 2) presenta una 


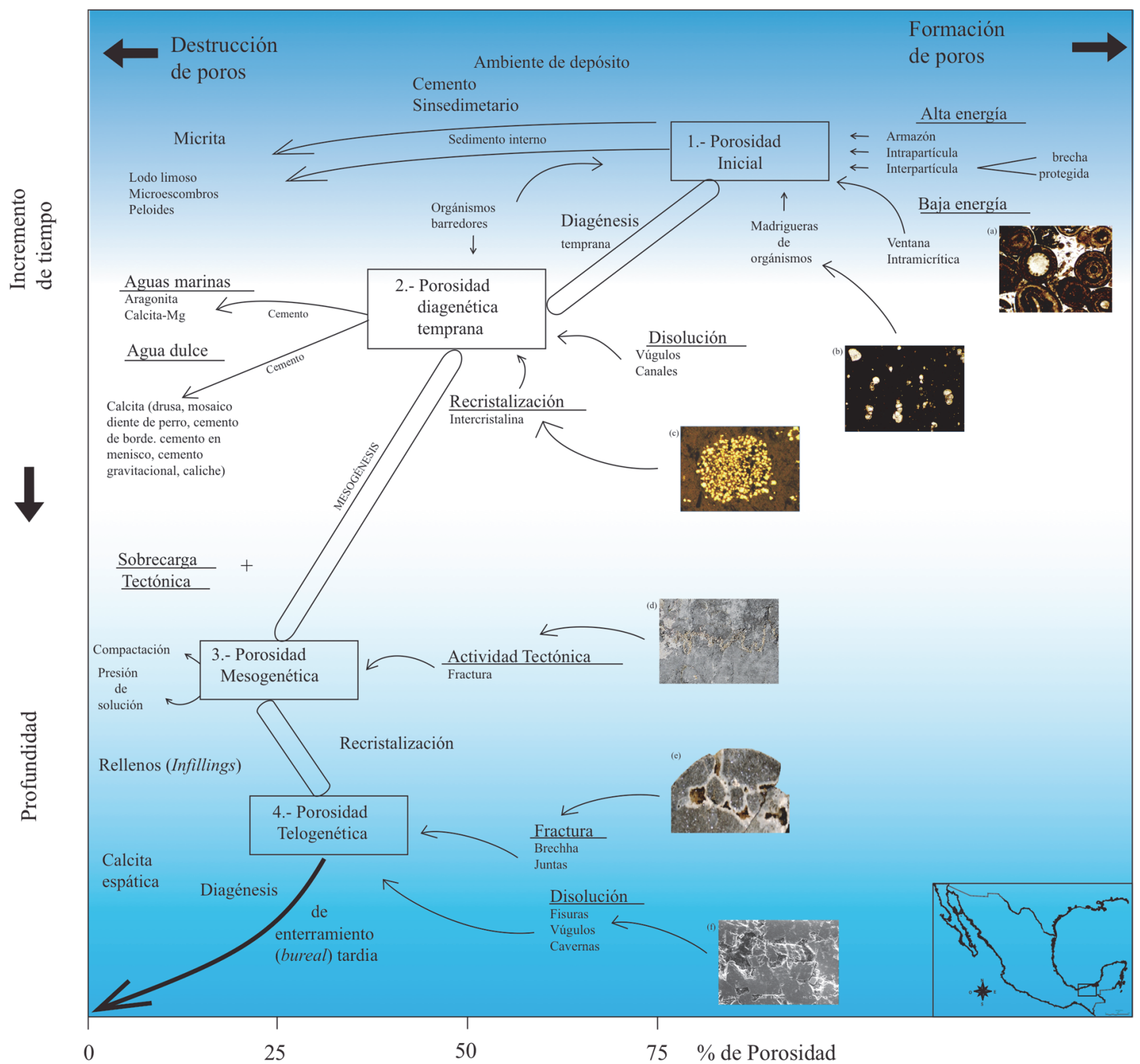

Figura 1. Esquema que muestra las etapas diagenéticas a las que puede ser sometido un sedimento y los cambios de porosidad relacionados. Modificado de Reeckmann y Friedman (1982). Las fotomicrografías ejemplifican cada uno de los fenómenos señalados en la figura mediante casos de la Cuenca del Sureste, donde: (a) ooide formado en ambiente de alta energía, (b) lodo micrítico con microfósiles, (c) microfósil reemplazado por pirita, (d) estilolita rellena de calcita, (e) microporosidad tipo vugs rellena parcialmente por calcita+cuarzo, (f) corrosión tardía de dolomita con neoformación de arcillas y sulfatos.

compleja evolución sedimentológica y tectónica (Holguín et al., 1985; Oviedo-Pérez, 1996; Guzmán-Vega y Mello, 1999; Goldhammer y Johnson, 2001; Guzmán-Vega et al., 2001a, b); González-Posadas, 2003; Aquino-López, 2004), pasando de facies carbonatadas de alta energía a sedimentos de cuenca desde el Jurásico al Cretácico con horizontes generadores de hidrocarburos. Un cambio profundo en la sedimentación se produce en el Cenozoico, representado por secuencias siliciclásticas con abundantes cambios de facies, ya que durante el Paleógeno y Mioceno la cuenca del Sureste de México funcionó como una depresión a lo largo del frente del cinturón de cabalgaduras de la Sierra Madre Oriental,
Sierra de Chiapas y Sierra de Juárez. Tal depresión ha sido denominada "cuenca ante-fosa" por Oviedo-Pérez (1996). Al final del relleno de dicha cuenca, la sedimentación fue fuertemente progradante, asociada a un gran aporte de sedimentos, principalmente arenosos. El depósito de éstos se produjo principalmente en un ambiente extensional en que la tectónica gravitacional ha actuado respondiendo a fenómenos de halokinesis (González-Posadas, 2003).

Entre el Triásico y principios del Jurásico se inició la separación de Pangea y la apertura del Golfo de México, generando una tectónica de fosas y pilares. Tales estructuras condicionaron la sedimentación posterior de modo que, 
durante el Calloviano-Oxfordiano, se produjo la formación de potentes espesores de evaporitas en la región.

Durante el Jurásico Tardío se produjo una amplia trasgresión que cubrió la mayor parte del área de la cuenca, y continuó durante el Kimmeridgiano, instalándose una plataforma carbonatada en un ambiente marino somero con comunicación abierta, en la que se depositaron carbonatos, limonitas y bancos oolíticos. Estos bancos se desarrollaron sobre los márgenes elevados de los altos de basamento preexistentes. Durante el Tithoniano se alcanzó la máxima trasgresión y se originaron las condiciones para depósitos de caliza arcillosa rica en materia orgánica, que constituye la principal roca generadora de la región.

Durante el inicio del Cretácico, la subsidencia y la extensión generaron fosas y pilares, con la consiguiente depositación de carbonatos de aguas someras en los pilares y de sedimentos lutíticos de aguas más profundas en las fosas. Una caída relativa del nivel del mar al principio del
Neocomiano marca el inicio del desarrollo de plataformas locales sobre los altos de basamento. En el Cenomaniano medio se origino una discordancia que esta relacionada a los fenómenos de karstificación, brechamiento y colapso de la mayoría de las plataformas.

El Cretácico Superior está representado por margas, con intercalaciones de brechas, calcarenitas, calizas y sedimentos bentoníticos de naturaleza arcillosa. Al final del Cretácico se produjeron cambios importantes en la reorganización de las placas tectónicas que dieron lugar a coalición entre los bloques de Chortis y Maya, ocasionando corrimientos y plegamientos de la Sierra de Chiapas. Tales eventos se asocian con la Orogénesis Laramide, que ocasiona la reactivación de fallas preexistentes, levantamiento regional, plegamiento y erosión, con la consiguiente producción de flujos de escombros.

Durante el Cenozoico existieron dos tipos de cuencas: (1) una cuenca ante-fosa que funcionó desde el Paleógeno

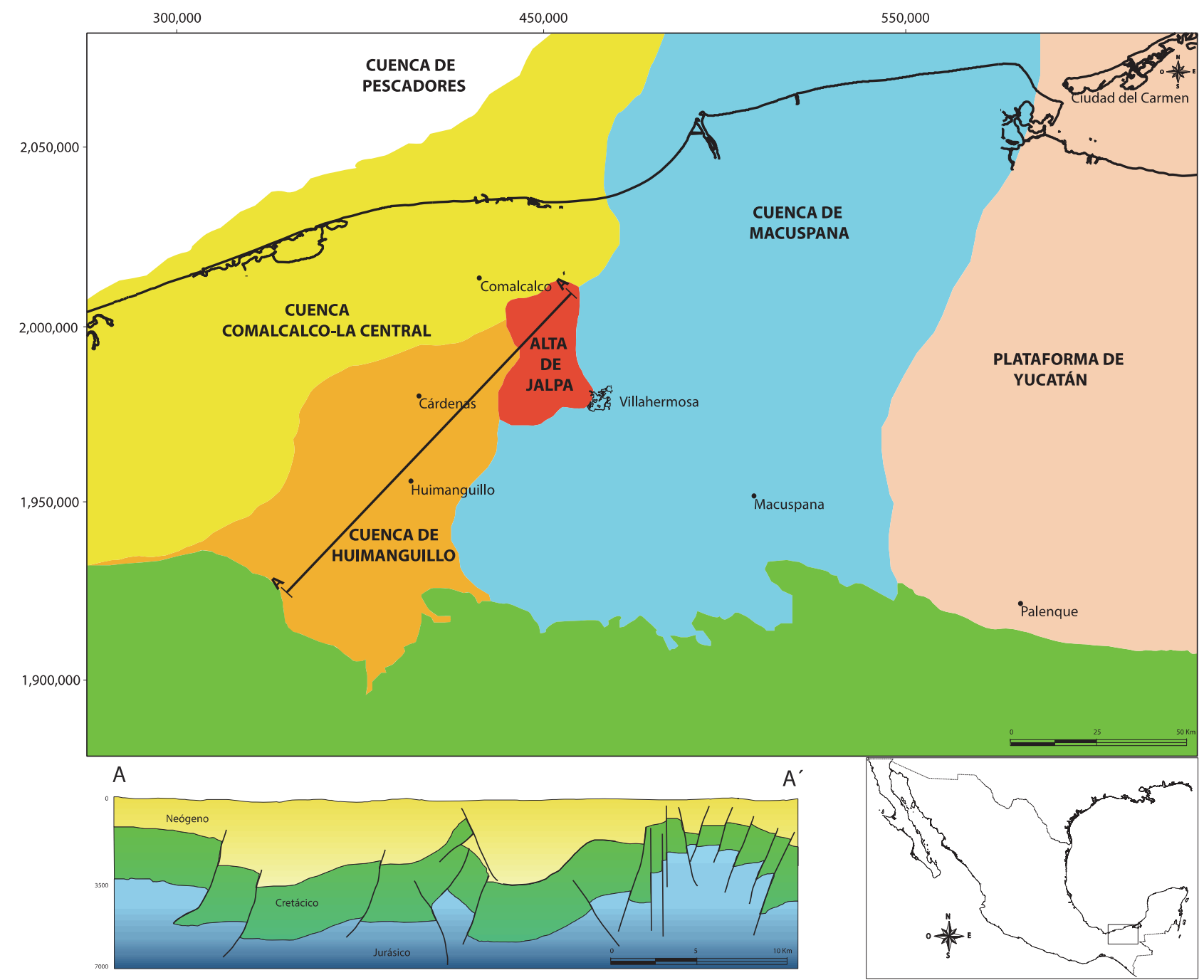

Figura 2. Localización geográfica de la Cuenca del Sureste acompanada de un corte esquemático ideal de la posible distribución de hidrocarburos, donde se muestra los horizontes del Jurásico y del Cretácico de donde provinieron las muestras analizadas. Ver distribución espacial en la Figura 3. Modificada de González-Partida et al. (2008). 
y hasta el Mioceno Tardío, y (2) una cuenca de relleno pasivo durante el Plioceno-Pleistoceno. La cuenca antefosa fue formada debido a los cinturones de pliegues y cabalgaduras de la Sierra Madre Oriental y Sierra de Chiapas, obedeciendo a una compensación isostática debida al peso del apilamiento de las cabalgaduras en el frente compresivo. Ello generó una flexura en la litosfera paralela al frente cabalgante, misma que corresponde a una cuenca ante-fosa. En dicha cuenca se identificaron (GonzálezPosadas, 2003) cuatro tectonosecuencias durante el Paleógeno (68.0 - 20.53 Ma), el Mioceno Temprano-Medio (20.53 - 11.7 Ma), el Mioceno Tardío (11.7 - 5.73 Ma), y el Plio-Pleistoceno (5.73 Ma al presente) que, en parte, sirven como sellos junto con las margas del Cretácico Superior.

\section{Metodología de trabajo}

El microscopio electrónico de barrido (SEM por sus siglas en inglés) utilizado en este estudio es del tipo JEOL JSM-6060LV y el analizador de imágenes (EDS por sus siglas en inglés) es del tipo Oxford Inca X-Sight y están instalados en los laboratorios de la Université de Lorraine (Francia) y en el Centro de Geociencias de la UNAM (México).

La técnica de tomografía digital computarizada (microtomografía digital 3D) es laboriosa y, de cierta forma, artesanal en el proceso de la preparación y montaje de la muestra. Ello, debido a lo novedoso de la misma y los pocos accesorios que se encuentran disponibles en el mercado. Todo el proceso de adquisición de la imagen, tratamiento y análisis digital dependen netamente de las capacidades y experiencia del operador, ya que se debe ajustar la mayoría de los parámetros de forma manual. La técnica de tomografía digital computarizada trabaja únicamente a partir de la diferencia de densidades, por lo que no se obtiene información sobre la composición química de la muestra. Las imágenes de salida obtenidas del tomógrafo son en escala de grises, con un total de 65536 diferentes tonos, con los cuales, a partir del uso de software especializado, es posible (1) establecer diferenciaciones de fases y lograr imágenes a colores según las densidades aisladas, (2) establecer rangos de densidad a los cuales se les pueden asignar diferentes gamas de color, y (3) realizar extracciones, adiciones, y cálculos avanzados de petrofísica, entre otras operaciones. La metodología de trabajo sigue los siguientes pasos referidos, respectivamente, a la selección, montaje, análisis, e interpretación de muestras:

(I) El primer paso consiste en realizar una correcta selección y corte de la muestra a estudiar. Cabe mencionar que existe una relación directa entre el tamaño de la muestra extraída (cortada) y la calidad de la imagen. Cuanto menor sea el tamaño de la muestra, mayor definición se puede obtener. Por ejemplo, para una muestra de $4 \mathrm{~mm}$ de diámetro se puede obtener un voxel de $1.9 \mu \mathrm{m}$ (un voxel es la unidad tridimensional usada en los sistemas computacionales, comparable a un pixel en dos dimensiones, de forma que un voxel de $1 \mu \mathrm{m}$ tiene un volumen de $1 \mu \mathrm{m}^{3}$ ).

(II) El siguiente paso consiste en montar y fijar la muestra sobre una base que puede ser de cristal, acrílico o de polímero (o que posea una densidad muy baja), ya que el sujetador no alcanza a llevar la muestra hasta el punto de emisión de rayos-X y un material de igual o mayor densidad que la de la muestra afectaría el resultado del escaneo. La muestra debe quedar lo más cercano a $90^{\circ}$ para que no haya movimiento al hacer la rotación y evitar en lo posible el efecto de "bailarina de ballet". En los siguientes pasos, se requiere el uso de dos computadoras (o "súpercomputadoras") con una gran capacidad de almacenamiento (como mínimo 100 veces mayor a una computadora normal): La primera de ellas es para la captura de las imágenes directas, y la segunda para generar la reconstrucción y análisis de imágenes por lo que esta debe ser un clúster, ya que el tamaño mínimo de los archivos reconstruidos suele ser del orden de $30 \mathrm{~GB}$, y con tratamientos digitales pueden aumentar $20 \mathrm{~GB}$ adicionales. En la etapa de adquisición de datos, es preciso realizar una calibración del equipo por cada muestra que se vaya a analizar, ya que la calibración depende del fenómeno que se necesite observar. Una vez realizada dicha calibración se ajustan todos los parámetros: voltaje, potencia, tiempo de exposición de la imagen, cantidad de imágenes, posicionamiento de la muestra, distancia entre la muestra y el emisor de rayos-X, y distancia entre el receptor y la muestra, entre otros parámetros. Todos los parámetros deben ser ajustados según el tipo de muestra para lograr la mejor definición y calidad de imagen posible, ya que los parámetros que funcionan para un tipo de muestras pueden no ser óptimos para otra. La forma de trabajar para la adquisición de imágenes es la siguiente: (1) el tomógrafo emite un haz de rayos-X que es capturado como una radiografía convencional en el receptor. (2) la muestra va girando para tomar tantas imágenes como se hayan programado, y (3) al final se unifican las imágenes y se hacen ajustes para programar la forma de tomar una foto. Un ajuste común es tomar 3 fotografías de cada giro con un tiempo de exposición de 750 milisegundos. De esas tres imágenes se hace un promedio y ésa es la imagen que se colecta (la máquina que realiza la adquisición de imágenes manda directamente la información a la computadora donde se hará el análisis). Mientras más imágenes se tengan al momento de hacer la reconstrucción, se obtendrá una mejor definición y calidad del modelo tridimensional, por lo que una buena tomografía para una muestra de diámetro de 4 mm puede tomar aproximadamente tres horas solamente para la adquisición de imágenes, sumando el protocolo de calibración, calentamiento del equipo, reconstrucción y análisis.

(III) El siguiente paso consiste en realizar la reconstrucción de imágenes a través de un software especializado y transformar las imágenes obtenidas en un modelo 3D. Con dicho software se puede también ajustar diversos parámetros para realizar correcciones a posibles 
errores en la alineación de la muestra, así como usar algunos filtros para mejorar las imágenes, entre otros parámetros. En este paso se requiere usar el clúster (mínimo con un procesador Xeon) antes mencionado. El equipo utilizado es un microscopio de rayos-X ZEISS Xradia Versa 510 con los siguientes componentes: (1) fuente de rayos- $\mathrm{X}$ de alto rendimiento, con fuente de transmisión sellada $(30-160$ $\mathrm{kV}$, máximo $10 \mathrm{~W}),(2)$ detectores de contraste optimizado, (3) sistema detector de doble etapa innovadora con torreta detector de múltiples objetivos en diferentes aumentos con centelladores optimizados para mayor contraste, (4) detector de $2000 \times 2000$ pixeles con supresor de ruido, (5) portamuestras de ultra-alta precisión con 8 grados de libertad, (6) capacidad de $15 \mathrm{~kg}$ para la muestra, y (7) tamaño mínimo de voxel de $70 \mu \mathrm{m}$ alcanzable con el máximo aumento.

\section{Material analizado y resultados}

\subsection{Rocas inalteradas}

Las muestras analizadas provienen de horizontes jurásicos y cretácicos entre la cuenca de Huimanguillo y Alto de Jalpan. Las rocas analizadas más antiguas son del Jurásico Superior (Kimmeridgiano), que corresponden a caliza y dolomía mesocristalina con microfracturas que alternan entre packstone a grainstone; les siguen bancos oolíticos (Figura 3), y calizas con textura original de wackestone, rudstone, grainstone, brecha, floatstone $\mathrm{y}$ mudstone, con peloides, intraclastos y bioclastos como granos del armazón. Los bioclastos incluyen ostrácodos de paredes gruesas, fragmentos de crinoideos y conchas de pelecípodos. La textura y composición originales indican que los sedimentos fueron depositados en ambientes marinos someros bajo condiciones de plataforma de alta energía (Figura 3). En estas rocas se encuentra localizada la mayor concentración de reservas de hidrocarburos, ya que los pozos son productores a nivel del Jurásico Superior (Kimmeridgiano) hasta niveles del Cretácico "medio", estas rocas presentan porosidad inter-partícula, intercristalina, cavidades de disolución móldica, microfracturas y estilolitas.

En el Cretácico Inferior, la caliza contiene lodo pelágico constituido por un wackestone de foraminíferos planctónicos del tipo globigerínidos y Cadosina con muy buena preservación, mostrándose secciones axiales, longitudinales y ecuatoriales. Sus cámaras se encuentran rellenas por calcita espática al igual que las paredes de sus conchas, y la roca contiene menos del $2 \%$ de radiolarios. La matriz presenta neomorfismo agradante de calcita micrítica a calcita espática. La roca, que corresponde a caliza de cuenca, presenta una porosidad de fábrica selectiva del tipo móldica, con permeabilidad baja. El periodo Cretácico "medio" está formado por calizas mudstone a wackestone recristalizado con porosidad intercristalina y microfracturas. Las rocas del Cretácico Superior y Paleógeno corresponden al sello y están constituidas por margas y lutitas.

\subsection{Minerales diagenéticos}

La roca inicial actualmente se encuentra fuertemente alterada por procesos diagenéticos de corrosión-disoluciónprecipitación generando el desarrollo de fracturas de disolución, microcavidades tipo vugs y dolomitas corroídas (Figuras 4 y 5). La sucesión paragenética de diagénesis determinada en este estudio está representada por dolomita $\rightarrow$ calcita $_{1} \rightarrow$ cuarzo $_{1} \rightarrow$ pirita $\rightarrow$ dolomita $_{5-7} \rightarrow$ calcita $_{2}$ $\rightarrow$ cuarzo $_{2} \rightarrow$ calcita $_{3} \rightarrow$ cuarzo $_{3} \rightarrow$ clorita $\rightarrow$ ceolita $\rightarrow$ arcillas $\rightarrow$ celestina $\rightarrow$ calcita $_{4}$ con hidrocarburos, aunque en otras partes de la cuenca se han observado más de 8 generaciones de dolomita y calcita en diferentes conjuntos de fracturas. Destaca la fuerte presencia de cuarzo rellenando microcavidades tipo vugs, fracturas y el reemplazamiento parcial de algunos fósiles por pirita, fenómeno muy característico en el campo petrolero de Cárdenas. Los minerales se encuentran tanto en forma de relleno de fracturas y brechas como en microcavidades tipo vugs. La mineralogía descrita fue corroborada por análisis de difracción de rayos-X y por microscopio electrónico de barrido. La mayoría de microcavidades tipo vugs están rellenas y presentan un zoneamiento de cuarzo-calcita, y las vetillas presentan una sucesión paragenética de origen diagenético, que va de dolomita inicial a cuarzo + celestina + calcita tardía, generalmente la dolomita esta corroída. La pirita framboidal, las arcillas y zeolitas generalmente ocupan espacios dejados por los cristales de dolomita y precipitan dentro de las microcavidades tipo vugs como una etapa intermedia a tardía. Información novedosa obtenida por medio de microtomografía de rayos-X (Figura 6) revela que: $\left(1^{\circ}\right)$ la mayoría de las microcavidades tipo vugs no están interconectadas, $\left(2^{\circ}\right)$ las muestras presentan abundante contenido de fósiles orientados de acuerdo a la estratificación y $\left(3^{\circ}\right)$ las microfracturas y nano-poros de la matriz son parcialmente responsables del desarrollo de las microcavidades tipo vugs.

Los vugs se formaron a partir de soluciones corrosivas que inicialmente generaron micro-brechas seguidas de un relleno parcial por cuarzo y calcita (Figura 5). La presencia y abundancia de cuarzo diagenético observado en estas muestras no es común en otros campos de la cuenca del Sureste.

\subsection{Fluidos Diagenéticos}

Los fluidos diagenéticos relacionados con los yacimientos de hidrocarburos de la cuenca del Sureste fueron caracterizados por medio del análisis microtermométrico de inclusiones fluidas (Tabla 1). Las inclusiones fluidas, objeto del estudio microtermométrico, fueron primarias y, para tal efecto, se emplearon los criterios de identificación enunciados por Roedder (1984), Goldstein y Reynolds (1994), Boiron y Dubessy (1994) y Goldstein (2001). 


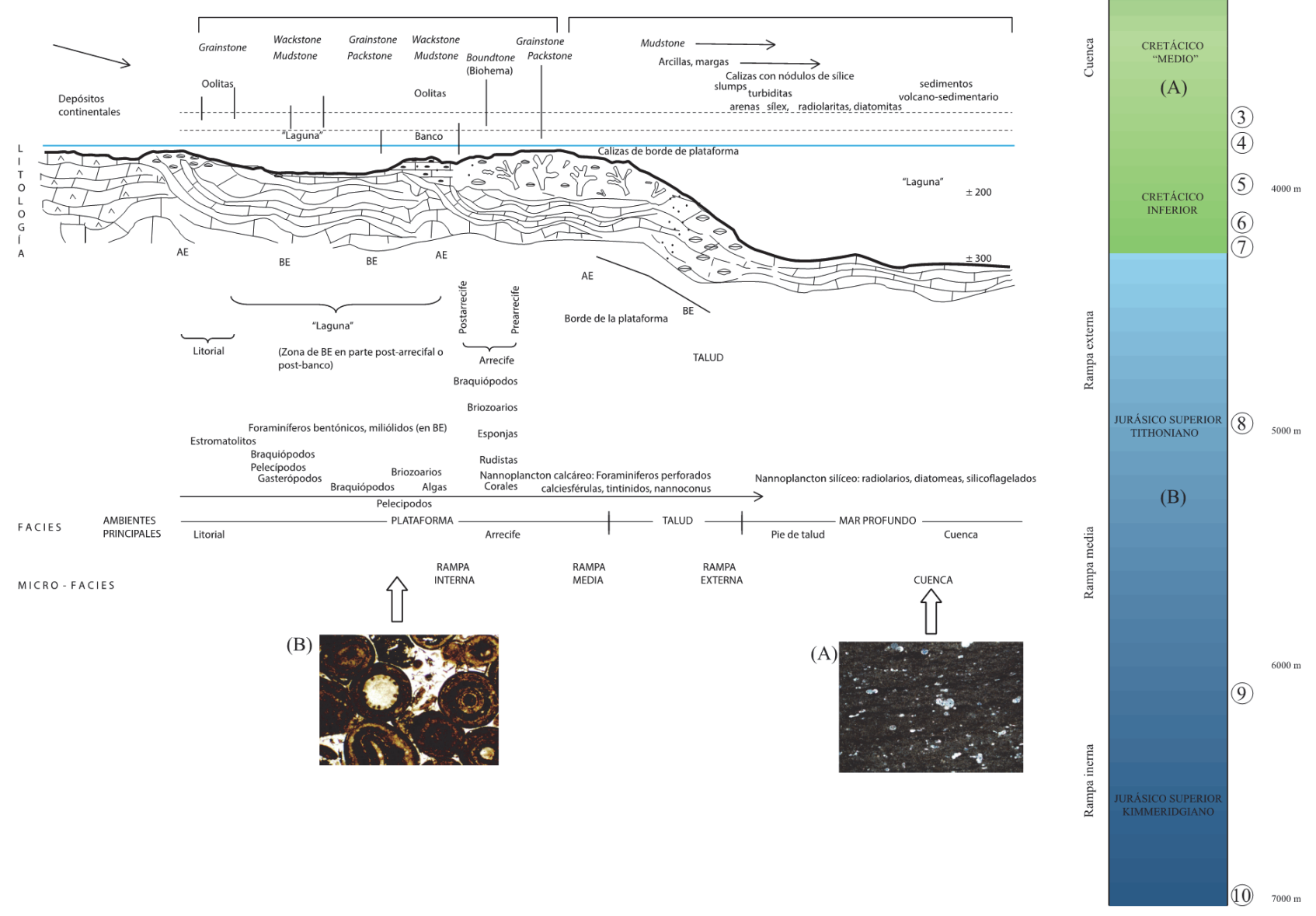

Figura 3. Características petrográficas de la roca primaria y su ambiente de formación. Las calizas del Jurásico corresponden a un ambiente de alta energía pasando, por transgresión marina, a un ambiente de cuenca en el Cretácico. Las muestras localizadas del 1 a 10 corresponden a las referidas en la Tabla 1. Modificada de Flügel (2004).

Dicho análisis abarca inclusiones en dolomita y calcita que se encuentran (1) en las rocas generadoras del TithonianoKimmeridgiano, (2) a lo largo de las rutas de migración de los hidrocarburos, y (3) en las rocas almacenadoras. Tanto en calcita como en dolomita se determinaron tres tipos de inclusiones fluidas con base en su contenido (Figura 6 y Tabla 1): (a) bifásicas acuosas $(\mathrm{L}+\mathrm{V})$, (b) bifásicas de hidrocarburos $(\mathrm{LHC}+\mathrm{V})$, y (c) trifásicas con líquidos acuosos e hidrocarburos inmiscibles $(\mathrm{L}+\mathrm{LHC}+\mathrm{V})$. De manera muy ocasional, algunas inclusiones fluidas presentan cristales hijos (S) de celestina, anhidrita, dolomita, o bitumen $(\mathrm{L}+\mathrm{LHC}+\mathrm{V}+\mathrm{S})$. Las inclusiones fluidas acuosas (L) son incoloras, con líquido dominante (generalmente con grado de relleno $\mathrm{F}=0.95$ ) y presentan formas alargadas, tubulares, rectangulares o prácticamente esféricas, con tamaños entre 5 y $10 \mu \mathrm{m}$. Las inclusiones bifásicas con hidrocarburos presentan coloraciones café-amarillentas, un grado de relleno inferior a las acuosas $(\mathrm{F}=0.80)$ y tamaños entre 30 y $80 \mu \mathrm{m}$. Las inclusiones con fluidos inmiscibles $(\mathrm{F}=0.85)$ presentan un predominio volumétrico de los hidrocarburos sobre las salmueras, generalmente entre $80 \mathrm{y}$ $85 \%$, y su tamaño varía entre 30 y $100 \mu \mathrm{m}$. Los tres tipos de inclusiones fluidas fueron comúnmente observados dentro de las mismas asociaciones de inclusiones fluidas, lo cual se interpreta como atrapamiento heterogéneo en presencia de fluidos inmiscibles. Para todos los casos, el cálculo de salinidades se realizó mediante las temperaturas de fusión del hielo y se utilizó la ecuación de estado de Bodnar (1993).

\section{Discusión y conclusión}

El entendimiento de los cambios producidos en una roca carbonatada desde su sedimentación hasta su conversión 

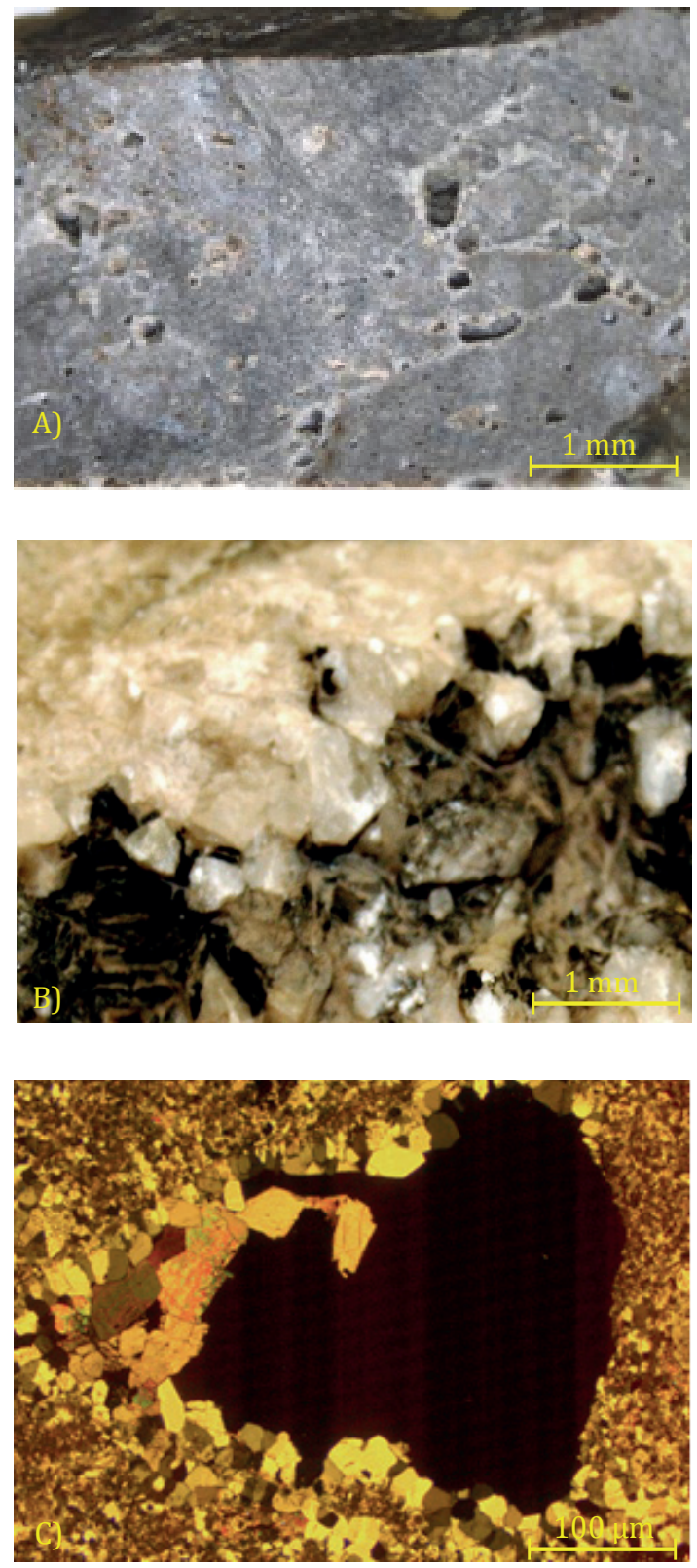
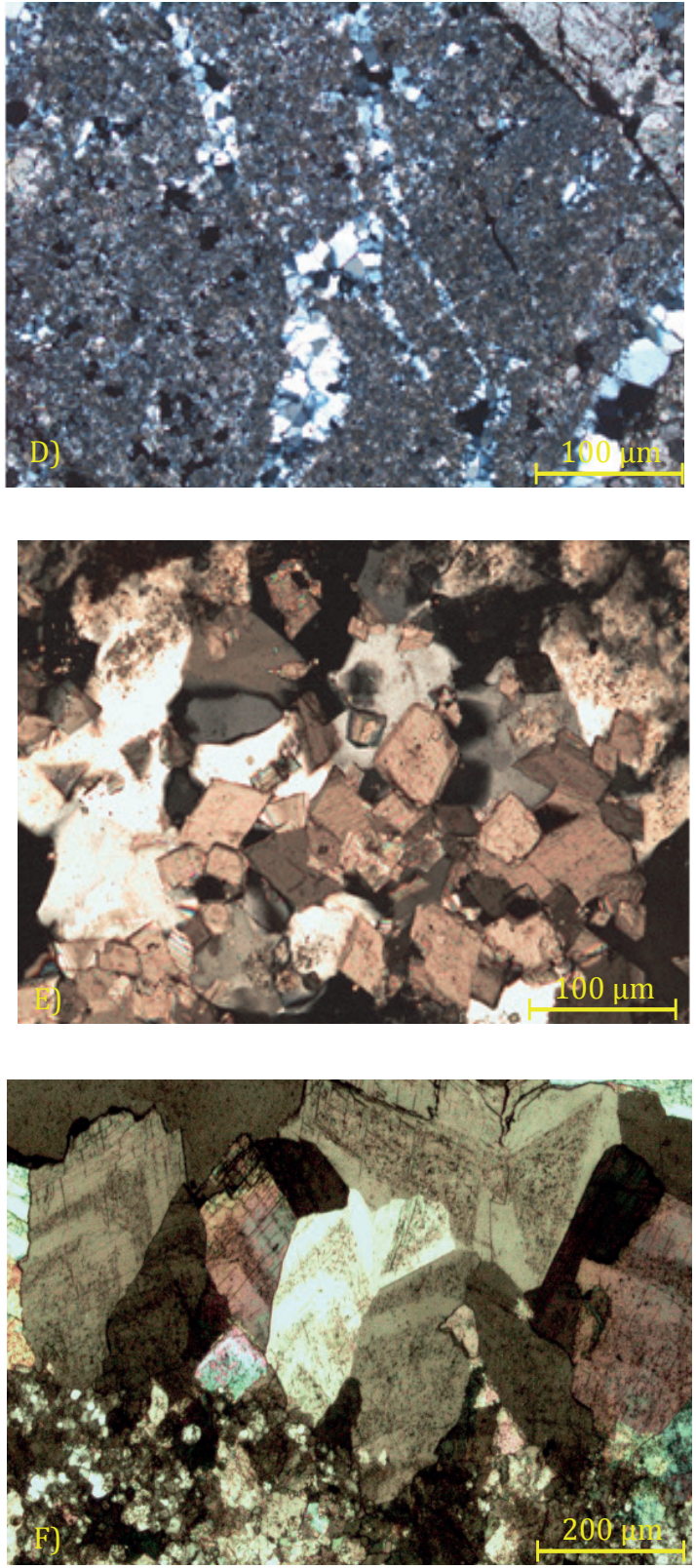

Figura 4. Fotomicrografías de la paragénesis de diagénesis en las muestras analizadas de la Cuenca del Sureste: (a) desarrollo y distribución de microporosidad tipo vugs, (b) drusa rellena de hidrocarburos muertos (chapopote) con cristales de calcita tipo "diente de perro", (c) microporosidad tipo vugs rellena parcialmente por dos generaciones de cuarzo y calcita al centro, (d) caliza cortada por vetillas de cuarzo microcristalino, (e) dolomita en una matriz tardía de cuarzo, (f) dolomita del tipo "silla de montar" que muestra microzonación conteniendo inclusiones fluidas. Clave: $\mathrm{Qz}=$ cuarzo, Do $=$ dolomita, $\mathrm{LP}=$ luz polarizada.

en un reservorio de hidrocarburos es un punto de crucial importancia para entender cómo funciona un sistema petrolífero. Los cambios composicionales y texturales de las rocas carbonatadas registran los cambios en las condiciones físico-químicas de los fluidos implicados en la historia diagenética de la roca. Ello incluye aspectos como la historia de interacción y expulsión de aguas connatas, la circulación de aguas de formación (salmueras de cuenca), la expulsión, circulación y acumulación de hidrocarburos líquidos y gaseosos, y la posible degradación térmica y/o biológica de los mismos. Por ello, no se puede entender el llenado de hidrocarburos en un reservorio sin un estudio profundo de la diagénesis de dichas rocas. Las nuevas herramientas de trabajo (e.g. SEM-EDS, microtomografía 3D de rayos-X) permiten actualmente entender los mecanismos de generación-destrucción de la porosidad ya que definen mejor las distribuciones espaciales de las diversas microestructuras asociados a los fenómenos geológicos que controlan el funcionamiento de un sistema petrolífero.

En los niveles profundos del Tithoniano-Kimmeridgiano, 

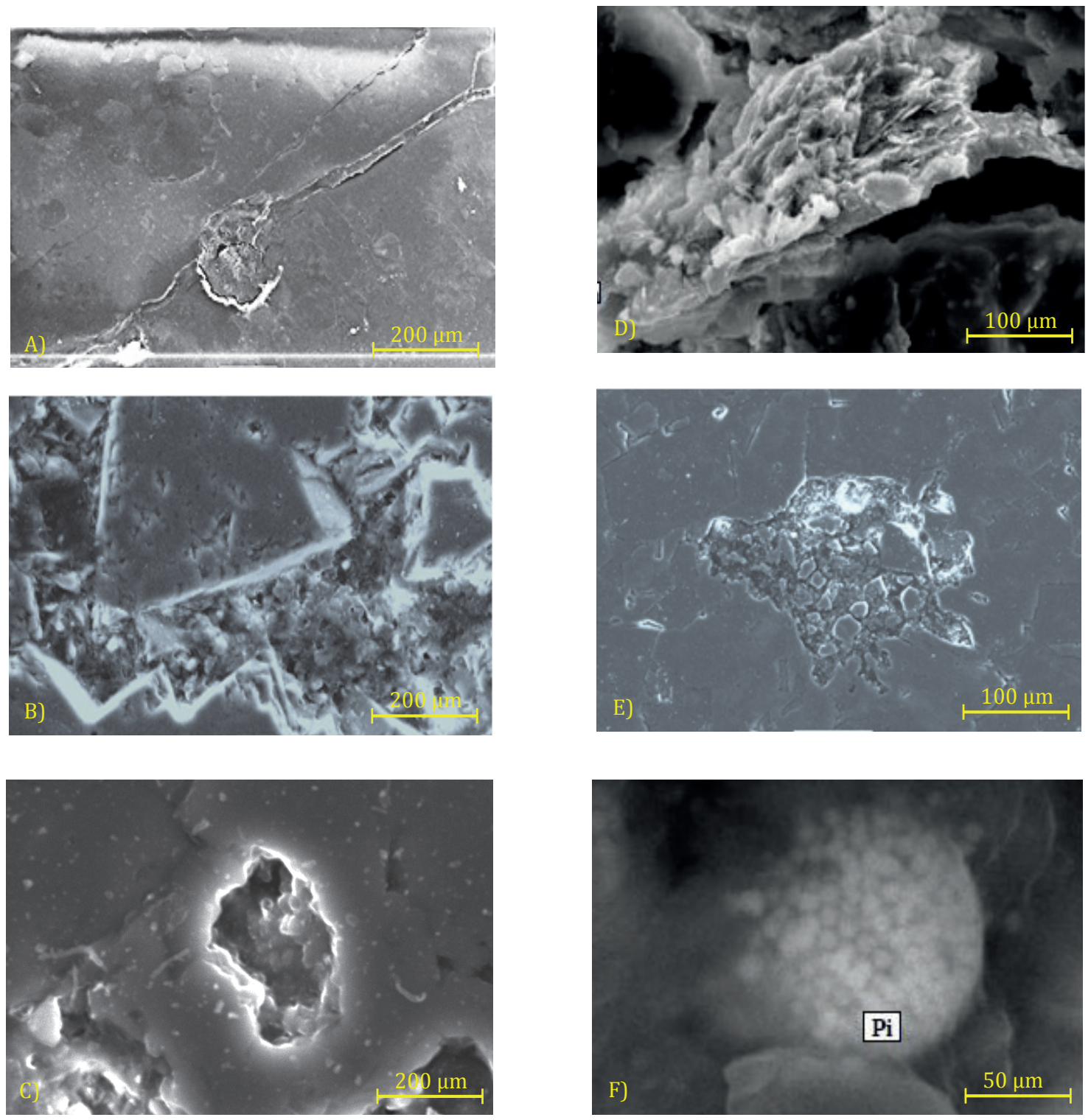

Figura 5. Imágenes de electrones retrodispersados en microscopio electrónico de barrido, donde: (a) dolomita parcialmente corroída y cementada por calcita y arcillas, (b) fracturas que interconectan microporosidad tipo vugs en una fase inicial de su formación, (c) microporosidad tipo vugs rellena de esférulas de sílice amorfa, (d) cristal de kaolinita (Ka), que se desarrolla entre el contacto de cristales de dolomita, (e) corrosión de cristales de dolomita que evoluciona al desarrollo de un micro-brecha, paso previo a la formación de microporosidad tipo vugs, (f) pirita framboidal (Pi). La escala de cada foto se expresa en $\mu \mathrm{m}$.

Tabla 1. Datos microtermométricos de inclusiones fluidas recopilados a partir de Martínez-Ibarra (1999), Martínez-Ibarra et al. (2003), González-Partida et al. (2004), Levresse et al. (2004, 2005a, b), Méndez-Ortiz et al. (2004, 2006), Bourdet et al. (2005), y Pironon et al. (2005). Clave: Th = temperatura de homogeneización, (*) Salmueras de $\mathrm{CaCl}_{2}+\mathrm{NaCl} . \mathrm{N}=$ número de inclusiones analizadas, $\mathrm{Tf}=$ temperatura de fusión final.

\begin{tabular}{|c|c|c|c|c|c|c|c|c|c|c|c|}
\hline \multirow{2}{*}{$\begin{array}{l}\text { Mineral } \\
\text { Calcita }\end{array}$} & \multirow{2}{*}{$\begin{array}{l}\text { Edad } \\
\text { Cretácico Superior }\end{array}$} & \multirow{2}{*}{$\frac{\text { Profundidad (m) }}{2920}$} & \multirow{2}{*}{$\frac{\mathbf{n}}{40}$} & \multicolumn{2}{|c|}{$\operatorname{Th}\left({ }^{\circ} \mathrm{C}\right)$} & \multicolumn{2}{|c|}{$\operatorname{Tf}\left({ }^{\circ} \mathrm{C}\right)$} & \multicolumn{2}{|c|}{$\begin{array}{c}\text { Salinidad } \\
\text { (wt. } \% \mathrm{NaCl} \\
\text { equiv.) }\end{array}$} & \multirow{2}{*}{$\frac{\text { Presión (bar) }}{\text { N/A }}$} & \multirow{2}{*}{$\begin{array}{l}\text { Observaciones } \\
\text { Vetilla con hidrocarburos }\end{array}$} \\
\hline & & & & 70 & -75 & -7.4 & $-\quad-8.3$ & 11 & -12 & & \\
\hline Dolomita & Cretácico Superior & 2930 & 43 & 98 & -105 & -3.7 & $-\quad-6.6$ & 6 & -10 & N/A & Vug con hidrocarburos \\
\hline Dolomita & Cretácico Inferior & 3800 & 50 & 115 & -165 & -18 & $-\quad-25$ & 20 & $-23 *$ & 500 & Fractura con hidrocarburos \\
\hline Calcita & Cretácico "medio" & 3850 & 60 & 115 & -120 & -18 & $-\quad-27$ & 20 & $-24 *$ & 380 & Vug con hidrocarburos \\
\hline Calcita & Tithoniano & 4000 & 80 & 85 & -125 & -18 & $-\quad-27$ & 20 & $-24 *$ & 600 & Fractura con hidrocarburos \\
\hline Calcita & Cretácico Inferior & 4200 & 65 & 135 & -146 & -6.6 & $-\quad-9.2$ & 10 & -13 & 400 & $V u g$ con hidrocarburos \\
\hline Dolomita & Cretácico "medio" & 4300 & 48 & 130 & -135 & -15 & $-\quad-29$ & 18 & $-25^{*}$ & 550 & Dolomita con hidrocarburos \\
\hline Dolomita & Tithoniano & 5000 & 50 & 128 & -150 & -15 & --18 & 18 & $-20 *$ & 780 & Dolomita con microfracturas con hidrocarburos \\
\hline Dolomita & Kimmeridgiano & 6850 & 62 & 108 & -121 & -7.1 & -20 & 12 & $-21 *$ & N/A & Dolomita en $v u g$ \\
\hline Dolomita & Kimmeridgiano & 7000 & 62 & 60 & -140 & -24 & -44 & 23 & $-29^{*}$ & 1200 & Inicio de diagénesis, fluidos sobrepresurizados con $\mathrm{CH}$ \\
\hline
\end{tabular}



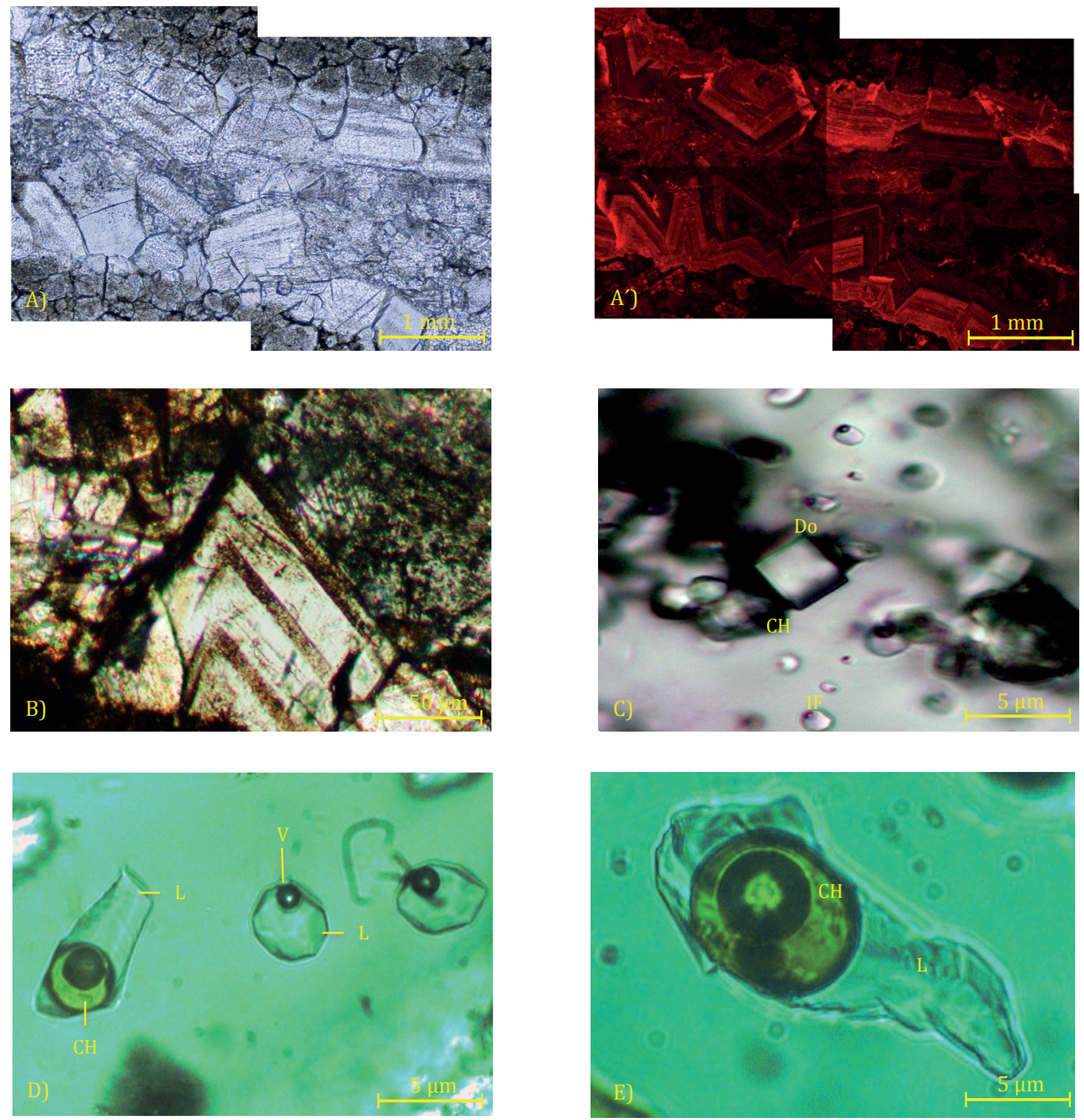

Figura 6. Fotomicrografías en que se observan (Ay A') una vetilla rellenando una fractura con microzoneamiento de dos generaciones de dolomita y calcita tardía al centro (A: luz polarizada; A': imagen de catodoluminiscencia), (B) detalle de un cristal de dolomita con bandas de crecimiento que contienen inclusiones fluidas primarias de salmueras acuosas y de hidrocarburos, $(\mathrm{C})$ dolomita con inclusiones fluidas de salmueras acuosas e hidrocarburos $\left(\mathrm{CH}_{4}\right)$ dentro de la misma asociación de inclusiones fluidas, (D) inclusiones fluidas de salmuera acuosa y de hidrocarburos dentro de la misma asociación de inclusiones fluidas, (E) inclusión fluida con salmuera acuosa e hidrocarburos. Clave: $\mathrm{HC}=$ hidrocarburos, $\mathrm{L}=$ líquido, $\mathrm{V}=$ vapor.

se presenta una salmuera cálcica, con inclusiones acuosas (Tabla 1) que presentan Th comprendidas entre 60 a $150^{\circ} \mathrm{C}$, salinidades entre $12 \%$ a $29 \%$ en peso equivalente en $\mathrm{CaCl}_{2}$, presiones entre 780 a 1200 bar (profundidades entre $\sim 5000$ y $\sim 7000 \mathrm{~m}$ ), y altos contenidos en $\mathrm{CH}_{4}$. Estas salmueras representan un episodio inicial en la circulación de fluidos, ligados a maduración de materia orgánica, en rocas sobrepresurizadas en que se desarrolló una densa red de fracturas hidráulicas, microcavidades tipo vugs, estilolitas y brechas. En la etapa de migración de los fluidos se genera el principal proceso de dolomitización (González-Partida et al., 2002, 2004, 2008; Levresse et al., 2004, 2005a, b), y se pasa de un régimen litostático a uno hidrostático con generación de brechas hidráulicas cementadas por dolomita y calcita tardía. Este cambio se produce a presiones entre 800 y 500 bar, con temperaturas entre 100 a $150^{\circ} \mathrm{C}$ (Martínez-Ibarra 1999; Bourdet et al., 2005; Levresse et al., 2005a, b; Pironon et al., 2005), y salinidades medias a altas (Tabla 1). Entre 3000 a $5000 \mathrm{~m}$ de profundidad predominan dos fenómenos diagenéticos principales: (1) el reemplazamiento de la roca 

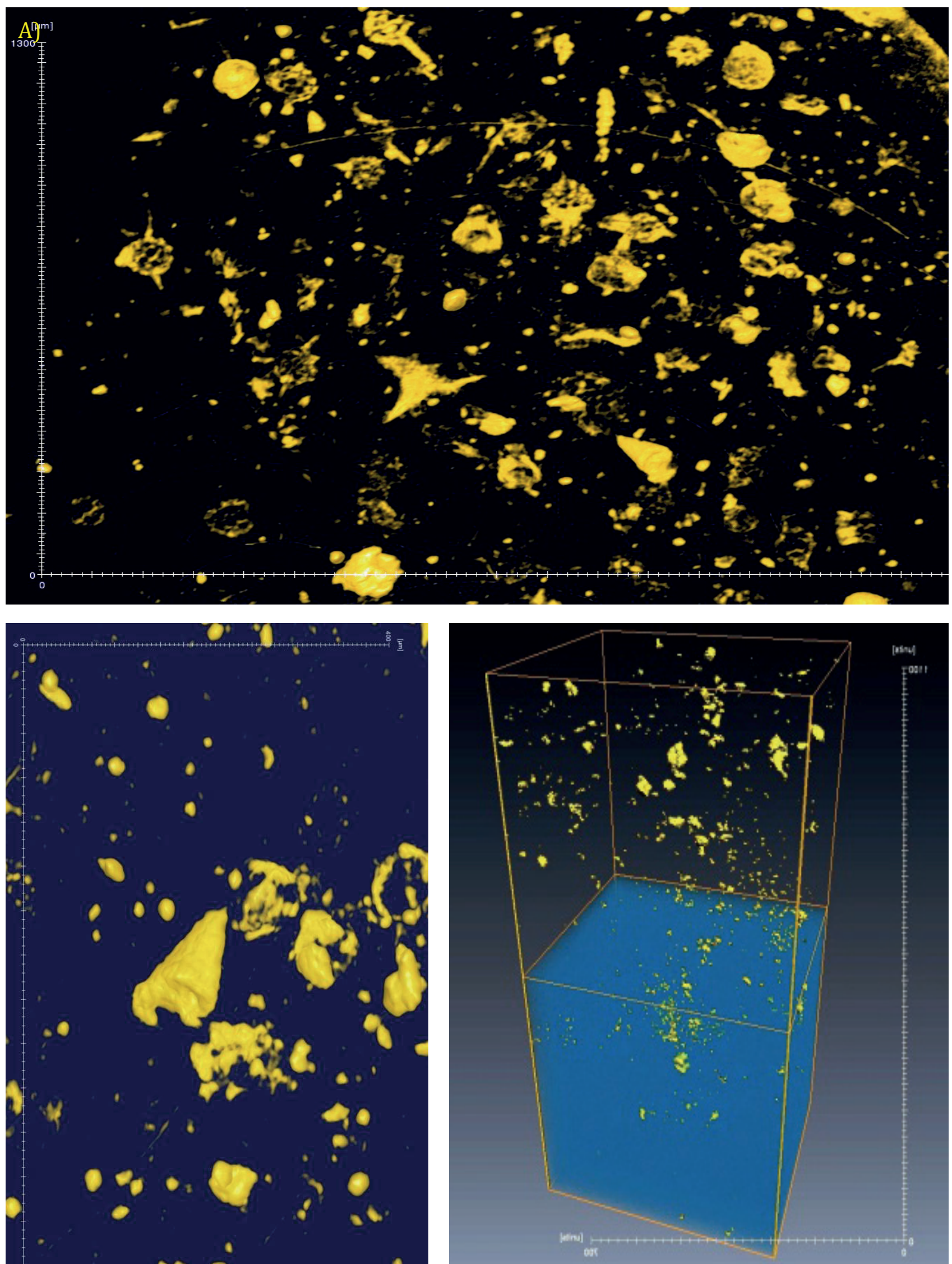

Figura 7. Imágenes integradas a partir del análisis de una muestra en microtomografía de rayos- $\mathrm{X}$ en $3 \mathrm{D}$ donde, al aplicar un filtro de densidad especial, resalta la distribución de los micro-foraminíferos (en amarillo) dispersos en el sedimento micrítico. 
por parte de dolomita (generación de dolomías de grano grueso), y (2) la cementación masiva por parte de calcita (rellenando microcavidades tipo vugs y fracturas), lo cual es congruente con el carácter cálcico de la salmuera. A 3000 $\mathrm{m}$ de profundidad, con predominio de rocas del Cretácico "medio" a Superior, el llenado de los reservorios se produjo a Th entre 130 a $150{ }^{\circ} \mathrm{C}$, por medio de salmueras con salinidades entre $6 \%$ a $12 \%$ equivalente en peso $\mathrm{NaCl}$, y a presiones hidrostáticas de los reservorios entre 400 a 600 bar (Martínez-Ibarra et al., 2003; Levresse et al., 2005a, b). En este evento es notoria una disminución en la salinidad de las salmueras y el incremento en el contenido de $\mathrm{CO}_{2}$, en relación a los estadios profundos donde la existencia de disolución de evaporitas, junto con los procesos de dolomitización, puede explicar la existencia de salmueras cálcicas. A las etapas de generación de porosidad se superponen etapas de corrosión generalizada que se pueden interpretar como resultado de enfriamiento conductivo de las salmueras de cuenca y/o su mezcla con fluidos diluidos de origen meteórico. Les sigue la precipitación de arcillas + calcita + cuarzo, un fenómeno que se repite al menos cinco veces durante la historia de la cuenca (secuenciación de fenómenos de generación y destrucción de la porosidad), generando así una sucesión paragenética altamente compleja. Se ha constatado principalmente que la porosidad disminuye debido con la precipitación de finos cristales de calcita y cuarzo (y, en menor cantidad, de sulfuros, sulfatos $\mathrm{y}$ arcillas). En último término, la precipitación de dichas asociaciones minerales produce la obturación en buena parte de las vías de migración de hidrocarburos, aun cuando permanece espectacularmente visible la microporosidad tipo vugs.

\section{Agradecimientos}

Agradecemos el apoyo financiero obtenido a partir de los proyectos UNAM-PAPIIT número IN101113-3 y de SENER-CONACyT número 207032 \# 08, y a los técnicos que apoyaron en la preparación de las muestras, figuras y material fotográfico, en especial al Ing. Juan Tomas Vázquez y al Ing. Erik Hugo Díaz Carreño. Asimismo, se agradece a los árbitros de este trabajo, cuyas observaciones permitieron mejorar su calidad.

\section{Referencias}

Ángeles-Aquino, F., Cantú-Chapa, A., 2001, Subsurface Upper Jurassic stratigraphy in the Campeche Shelf, Gulf of Mexico, en Bartolini, C., Buffler, R.T., Cantú-Chapa, A. (eds.), The western Gulf of Mexico Basin: Tectonics, sedimentary basins, and petroleum systems: American Association of Petroleum Geologists Memoir, $75,343-352$.

Aquino-López, J.A., 2004, Sureste Basin, Mexico and associated subbasins: An update and future potential: Tulsa, Oklahoma, E.U.A., American Association of Petroleum Geologists, 1-7.
Bathurst, R.G.C., 1975, Carbonate sediments and their diagenesis: Amsterdam, Holanda, Elsevier, 660 p.

Bazin, B., Borsse, É., Sommer, F., 1997a, Chemistry of oil-fields brines in relation to diagenesis of reservoirs 1 . Use of mineral stability fields to reconstruct in situ water composition. Example of the Mahakam basin: Marine and Petroleum Geology, 14 (5), 481-495.

Bazin, B., Borsse, É., Sommer, F., 1997b, Chemistry of oil-fields brines in relation to diagenesis of reservoirs 2 . Reconstruction of paleo-water composition for modeling illite diagenesis in the Greater Alwyn area (North Sea): Marine and Petroleum Geology, 14 (5), 497-511.

Bickle, M.J., McKenzie, D., 1987, The transport of heat and matter by fluids during metamorphism: Contributions to Mineralogy and Petrology, 95 (3), 384-392.

Bodnar, R.J., 1993, Revised equation and table for determining the freezing point depression of $\mathrm{H}_{2} \mathrm{O}-\mathrm{NaCl}$ solutions: Geochimica et Cosmochimica Acta, 57, 683-684.

Boiron, M.C., Dubessy, J., 1994, Determination of fluid inclusion composition: microanalytical techniques, en DeVivo, B., Frezzotti, M.L. (eds.), Fluid inclusions in minerals: methods and applications: Pontignano-Siena, Italia, Short course of the IMA working group "Inclusions in Minerals", International Mineralogical Association, $45-71$.

Bourdet, J., Pironon, J., Levresse, G., Tritlla, J., González-Partida, E., 2005, Oil field crosscut by a salt diapir, consequences on fluid migrations: The case of Chuc oil field, Southern Mexico: Proceedings XVIII ECROFI (CD-ROM.), Siena, Italia, edición en CD-ROM.

Budd, D.A., Saller, A.H., Harris, P.M., 1995, Unconformity and porosity in carbonate strata: American Association of Petroleum Geologists Memoir, 63, 313.

Cantú-Chapa, A., Ortuño-Maldonado, E., 2003, The Tithonian (Upper Jurassic) Edzna Formation, an important hydrocarbon reservoir on the Bay of Campeche continental shelf, Gulf of Mexico, en Bartolini, C., Buffler, R.T., Blickwede, J. (eds.), The Circum Gulf of Mexico and the Caribbean: Hydrocarbon habitats, basin formation, and plate tectonics: American Association of Petroleum Geologists Memoir, 79, 305-311.

Chillingarian, G.V., Mazullo, S.J., Rieke, H.H. (eds.), 1992, Carbonate reservoir characterization: a geologic-engineering analysis, part I-II: Amsterdam, Holanda, Elsevier, 639 p.

Choquette, P.W., Pray, L.C., 1970, Geologic nomenclature and classification of porosity in sedimentary carbonates: American Association of Petroleum Geologists Bulletin, 54, 207-250.

Esteban, M., 2005, Notas del curso de Carbonatos, PEMEX-UNAM, Villahermosa, Tabasco, Junio del 2005, $200 \mathrm{p}$.

Esteban, M., Taberner, C., 2005, The burial of carbonate reservoirs ("The rest of the story"): American Association of Petroleum Geologists Distinguished Lecture, 2-4.

Flügel, E., 2004, Microfacies of carbonate rocks. Analysis, interpretation, and application: Berlin - Heidelberg, Alemania, Springer, $976 \mathrm{p}$.

Goldhammer, R.K., Johnson, C.A., 2001, Middle Jurassic - Upper Cretaceous paleogeographic evolution and sequence-stratigraphic framework of the Northwest Gulf of México rim, en Bartolini, C., Buffler, R.T., Cantú-Chapa, A. (eds.), The western Gulf of Mexico Basin: Tectonics, sedimentary basins, and petroleum systems: American Association of Petroleum Geologists Memoir, 75, 45-81.

Goldstein, R.H., Reynolds, T.J., 1994, Systematics of fluid inclusions in diagenetic minerals: Tulsa, Oklahoma, EUA, SEPM Short Course, $31,199 \mathrm{p}$.

Goldstein, R.H., 2001, Fluid inclusions in sedimentary and diagenetic systems: Lithos, 55, 159-193.

González-Partida, E., Carrillo-Chávez, A., Grimmer, J., Pironon, J., 2002, Petroleum-rich fluid inclusions in fluorite, Purisima mine, Coahuila, Mexico: International Geology Review, 44, 755-764.

González-Partida, E., Carrillo-Chávez, A., Grimmer, J., Pironon, J., Mutterer, J., Levresse, G., 2003, Geochemical evolution of mineralizing fluids at the fluorite La Encantada - Buenavista district: a Mississippi Valley Type deposit: Ore Geology Reviews, 23, 107-124. 
González-Partida, E., Levresse, G., Tritlla, J., Carrillo-Chávez, A., Pironon, J., Oviedo-Pérez, A.E., Martínez-Kemp, H.L., González-Posadas, F., Priftuli, E., 2004, Fossil fluids from Saramako petroleum field, Mexico: Actas, IV Reunión Nacional de Ciencias de la Tierra, Querétaro, Qro, México, 101.

González-Partida, E., Camprubí, A., Canet, C., González-Sánchez, F., 2008, Fisicoquímica de salmueras e hidrocarburos en cuencas petroleras y en depósitos minerales tipo Mississippi Valley y asociados. Parte II: ejemplos de la Cuenca de Sabinas y la Cuenca del Sureste, México: Boletín de la Sociedad Geológica Mexicana, 60 (1), 23-42.

González-Posadas, F., 2003, Evolución geológica durante el Cenozoico en el área Chiapas-Tabasco, Cuenca del Sureste, México: México, D.F., Dirección de Estudios de Posgrado de la Facultad de Ingeniería, Universidad Nacional Autónoma de México, tesis de maestría, 200 p.

Guzmán-Vega, M.A., Mello, M.R., 1999, Origin of oil in the Sureste Basin, México: American Association of Petroleum Geologists Bulletin, 83 (7), 1068-1095.

Guzmán-Vega, M.A., Castro, L.O., Román-Ramos, J.R., Medrano-Morales, L., Valdéz, L. C., 2001a, El origen del petróleo en las sub-provincias Mexicanas del Golfo de México: Boletín de la Asociación Mexicana de Geólogos Petroleros, 49 (1), 31-46.

Guzmán-Vega, M.A., Ortíz, L.C., Román-Ramos, J.R., Medrano-Morales, L., Valdéz, L.C., Vázquez-Covarrubias, E., Ziga-Rodríguez, G., 2001b, Classification and origin of petroleum in the Mexican Gulf Coast Basin: an overview, en Bartolini, C., Buffler, R.T., CantúChapa, A. (eds.), The western Gulf of Mexico Basin: Tectonics, sedimentary basins, and petroleum systems: American Association of Petroleum Geologists Memoir, 75, 127-142.

Hanor, J.S., 1987, Origin and migration of subsurface sedimentary brines: SEMP Society for Sedimentary, SEPM Short Course 21, $255 \mathrm{p}$.

Hanor, J.S., 1994, Origin of saline fluids in sedimentary basins: Geological Society of America Special Publication, 78, 151-174.

Hanor, J.S., Kharaka, Y.K., Land, L.S., 1988, Geochemistry of waters in deep sedimentary basins: Geology, 16, 560-561.

Holguín, N., 1985, Evaluación geoquímica del sureste de México: Boletín de la Asociación Mexicana de Geólogos Petroleros, 37, 3-48.

Holguín, N., Brooks, J.M., Román-Ramos, J.R., Bernard, B.B., LaraRodríguez, J., Zumberge, J.E., Medrano-Morales, L., Rosenfeld, J., De Farago, M., Maldonado-Villalón, R., Martínez-Pontvianne, G., 2005, Estudio regional de manifestaciones superficiales de aceite y gas en el sur del Golfo de México, su origen e implicaciones exploratorias: Boletín de la Asociación Mexicana de Geólogos Petroleros, 52 (1), 20-41.

Horsfield, B., Rullkötter, J., 1994, Diagenesis, catagenesis, and metagenesis of organic matter, en Magoon, L.B., Dow, W.G. (eds.), The petroleum system-from source to trap: American Association of Petroleum Geologists Memoir, 60, 189-199.

Kharaka, Y.K., Hull, R.W., Carothers, W.W., 1985, Water-rock interactions in sedimentary basins, en Gautier, D.L., Kharaka, Y.K., Surdam, R.C. (eds.), Relationship of organic matter and mineral diagenesis, Society of Economic Paleontologists and Mineralogists Short Course, 17, 79-116.

Kharaka, Y.K., Hanor, J. S., 2004, Deep fluids in the continents: I. Sedimentary basins, en Drever, J.I., Holland, H.D., Turekian, K.K. (eds.), Treatise on geochemistry, Surface and groundwater weathering and soils: Oxford, UK, 5 (16), Elsevier, 499-540.

Levresse, G., González-Partida, E., Camprubí, A., Carrillo-Chávez, A., Tritlla, J., Priftuli, E., Pironon, J., Sánchez-Trejo, A., PancardoCeballos, A., León-Ventura, R., Casimiro-Contreras, A., 2004, Fossil fluids from Pol petroleum field, Mexico: Official Program \& Abstract Book, AAPG European Region Conference with GSA, Prague, 90 p.

Levresse, G., Tritlla, J., González-Partida, E., Pironon, J., Teinturier, S., Priftuli, E., Oviedo-Pérez, A.E., Martinez-Kemp, H.L., GonzálezPosadas, F., 2005a, Evidence of hyperbaric ancient reservoirs in the Saramako oil field, SE Mexico: Proceedings XVIII ECROFI, Siena, Italia, edición en CD-ROM.

Levresse, G., González-Partida, E., Pironon, J., Tritlla, J., Priftuli, E., Sánchez-Trejo, A., 2005b, High pressure oil filling as recorded in fluid inclusions: the case of Pol oil field, Southern Mexico: Proceedings XVIII ECROFI, Siena, Italia, edición en CD-ROM.

Longman, M.W., 1980, Carbonate diagenetic textures from nearshore diagenetic environments: American Association of Petroleum Geologists Bulletin, 64, 461-487.

Lucia, J.F., 1995, Rock-fabric / petrophysical classification of carbonate pore space for reservoir characterization: American Association of Petroleum Geologists Bulletin, 79 (9), 1275-1300.

Magoon, L.B., Hudson, T.L., Cook, H.E., 2009, Pimienta-Tamabra - Un sistema gigante súper-cargado de petróleo en el sur del Golfo de México, en Clark, K.F., Salas-Pizá, G., Cubillas-Estrada, R. (eds.), Geología Económica de México: Pachuca, Hidalgo, Servicio Geológico Mexicano - Asociación de Ingenieros Mineros, Metalurgistas y Geólogos de México, 185-226.

Martínez-Ibarra, R., 1999, Estudio de inclusiones fluidas en dolomita asociada a emplazamiento de hidrocarburos: Parte sur del campo Cantarell, zona marina-Campeche: México, D.F., Instituto de Geología, Universidad Nacional Autónoma de México, tesis de maestría, $90 \mathrm{p}$.

Martínez-Ibarra, R., Tritlla, J., Cedillo-Pardo, E., Grajales-Nishimura, J.M., Murillo-Muñetón, G., 2003, Brine and hydrocarbon evolution during the filling of the Cantarell Oil Field (Gulf of Mexico): Journal of Geochemical Exploration, 78-79, 399-403.

McCulloch, T.H., Naeser, N.D., 1989, Thermal history of sedimentary basins: introduction and overview, en Naeser, N.D., McCulloch, T.H. (eds.), Thermal history of sedimentary basins: New York, E.U.A., Springer, 1-11.

Medrano-Morales, L., Romero, M., 1993, Caracterización geoquímica de las rocas generadoras de los sistemas petrolíferos del Jurásico Superior en el área Marina de Campeche, en I Simposio de Geología de Subsuelo, Campeche, México, Asociación Mexicana de Geólogos Petroleros, 5-16.

Méndez-Ortiz, B., Carrillo-Chávez, A., Tritlla, J., Levresse, G., GonzálezPartida, E., Oviedo-Pérez, A.E., Martínez-Kemp, H.L., GonzálezPosadas, F., Clara-Valdés, L., 2004, Chemical characterization of brines from selected oil fields, Tabasco, México: San Francisco, E.U.A., American Geophysical Union, Fall Meeting, V31A-1421.

Méndez-Ortiz, B., Carrillo-Chávez, A., González-Partida, E., GonzálezPosadas, F., Martínez-Kemp, H.L., 2006, Chemistry of petroleum brine from oilfields at southeast México: Journal of Geochemical Exploration, 89, 278-280.

Moore, C.H., 1979, Porosity in carbonate rock sequences, geology of carbonate porosity: American Association of Petroleum Geologists Continuing Education Course Note Series 11, A1-A14.

Oviedo-Pérez, A.E., 1996, Evolución Neógena de las Cuencas Terciarias del Sureste: México, D.F., Universidad Nacional Autónoma de México, tesis de maestría, $91 \mathrm{p}$.

Petróleos Mexicanos, 2011, Las reservas de hidrocarburos de México: México, D.F., Pemex Exploración y producción, 121 p.

Petróleos Mexicanos, 2012, Situación Actual y Perspectivas de Pemex, en Expo foro 2013, México, D.F., 1-8.

Pironon, J., Lhomme, T., Bourdet, J., Levresse, G., González-Partida, E., Tritlla, J., Carrillo-Chávez A., 2005, Study of petroleum and aqueous inclusions in carbonate reservoirs: a necessary adaptation: Proceedings XVIII ECROFI (CD-ROM.), Siena, Italia, edición en CD-ROM.

Purser, B.H., Tucker, M.E., Zenger, D.H., 1994, Problems, progress and future research concerning dolomites and dolomitization: A Volume in Honour of Dolomieu: Oxford, UK, Black Publishing Ltd. 464 p.

Reeckmann, A., Friedman, G.M., 1982, Exploration for Carbonate Petroleum Reservoirs: New York, E.U.A., John Wiley and Sons, $213 \mathrm{p}$.

Roedder, E., 1984, Fluid inclusions: Mineralogical Society of America, $12,646 \mathrm{p}$.

Rosenfeld, H.J., 2002, El potencial económico del Bloque de Yucatán en México, Guatemala y Belice: Boletín de la Sociedad Geológica Mexicana, 55, 30-37. 
Salas, J., Taberner, C., Esteban, M., Ayora, C. 2007. Hydrothermal dolomitization, mixing corrosión and deep burial porosity formation: numerical results from 1-D reactive transport models: Geofluids, 7 (2), 99-111.

Santamaría, D., 2000, Organic geochemistry of Tithonian source rocks and associated oils from the Sonda de Campeche, México: Aachen, Alemania, Universität Aachen, tesis doctoral, $190 \mathrm{p}$.

Santamaría, D., Horsfield, B., 2000, La Evolución térmica de las rocas generadoras del Tithoniano en el Área Marina de Campeche, México: Boletín de la Asociación Mexicana de Geólogos Petroleros, 49 (1-2), 116-136.
Manuscrito recibido: Agosto 10, 2014.

Manuscrito corregido recibido: Junio 6, 2015.

Manuscrito aceptado: Junio 9, 2015. 